\title{
Role of dexmedetomidine as adjuvant in postoperative sciatic popliteal and adductor canal analgesia in trauma patients: a randomized controlled trial
}

\author{
Vanita Ahuja ${ }^{1}$, Deepak Thapa ${ }^{1}$, Anjuman Chander $^{1}$, Satinder Gombar ${ }^{1}$, Ravi Gupta $^{2}$, and Sandeep Gupta ${ }^{2}$ \\ 'Department of Anesthesiology and Intensive Care, Government Medical College and Hospital, Chandigarh, India \\ ${ }^{2}$ Department of Orthopedics, Government Medical College and Hospital, Chandigarh, India
}

Received April 29, 2019

Revised December 1, 2019

Accepted December 19, 2019

\section{Correspondence}

Anjuman Chander

Department of Anesthesiology and Intensive Care, Government Medical

College and Hospital, Sector 32,

Chandigarh 160032, India

Tel: +91-9888443570

Fax: +91-172-2608488

E-mail: achander08@gmail.com

Previous presentation at conferences: The 4th National Conference of Indian Society of Pain Clinicians, 16-18th Nov. 2018, Lucknow, India.
Background: The effect of dexmedetomidine as an adjuvant in the adductor canal block (ACB) and sciatic popliteal block (SPB) on the postoperative tramadol-sparing effect following spinal anesthesia has not been evaluated.

Methods: In this randomized, placebo-controlled study, ninety patients undergoing below knee trauma surgery were randomized to either the control group, using ropivacaine in the $A C B+S P B$; the block Dex group, using dexmedetomidine + ropivacaine in the $A C B+S P B$; or the systemic Dex group, using ropivacaine in the ACB $+\mathrm{SPB}+$ intravenous dexmedetomidine. The primary outcome was a comparison of postoperative cumulative tramadol patient-controlled analgesia (PCA) consumption at 48 hours. Secondary outcomes included time to first PCA bolus, pain score, neurological assessment, sedation score, and adverse effects at $0,5,10,15$, and 60 minutes, as well as $4,6,12,18,24,30,36,42$, and 48 hours after the block.

Results: The mean \pm standard deviation of cumulative tramadol consumption at 48 hours was $64.83 \pm 51.17 \mathrm{mg}$ in the control group and $41.33 \pm 38.57 \mathrm{mg}$ in the block Dex group $(P=0.008)$, using Mann-Whitney U-test. Time to first tramadol PCA bolus was earlier in the control group versus the block Dex group $(P=0.04)$. Other secondary outcomes were comparable.

Conclusions: Postoperative tramadol consumption was reduced at 48 hours in patients receiving perineural or systemic dexmedetomidine with ACB and SPB in below knee trauma surgery.

Key Words: Analgesia; Dexmedetomidine; Lower Extremity; Nerve Block; Pain, Postoperative; Patient Satisfaction; Ropivacaine; Tramadol; Wounds and Injuries.

\section{INTRODUCTION}

Pain related to trauma surgery is frequently severe, but remains undertreated $[1,2]$. Opioids and non-steroidal antiinflammatory drugs have been recently questioned due to undesirable adverse effects in a multi-trauma patient having neurologic and respiratory impairment $[2,3]$. In con- trast, regional analgesia confers site-specific pain relief and prevents sensitization for the development of chronic pain [3].

Epidural analgesia is associated with many side-effects, which include hypotension, urinary retention, a block of the non-operated limb, impaired mobilization, post-dural puncture headaches, epidural hematoma, nerve injury, (c) This is an open-access article distributed under the terms of the Creative Commons Attribution Non-Commercial License (http://creativecommons.org/licenses/by-nc/4.0/), which permits unrestricted non-commercial use, distribution, and reproduction in any medium, provided the original work is properly cited.

(C) The Korean Pain Society, 2020
Author contributions: Vanita Ahuja: Writing/manuscript preparation; Deepak Thapa: Writing/manuscript preparation; Anjuman Chander: Investigation; Satinder Gombar: Supervision; Ravi Gupta: Formal analysis; Sandeep Gupta: Formal analysis. 
and meningitis [4]. Otherwise, ultrasound-guided peripheral nerve blocks (PNB) continue to be used, due to clinically safety and cost effectiveness [5]. Use of combined femoral and sciatic blocks offer a practical alternative to epidural analgesia for unilateral knee replacements [6]. Lollo et al. [7] reported no major nerve injury or deficit among 357 popliteal sciatic nerve blocks with either femoral or saphenous nerve blocks performed. YaDeau et al. [8] compared ultrasound-guided sciatic and adductor canal blocks (ACB) with intravenous (IV) dexamethasone and/or buprenorphine, and found there was no difference in pain with movement at 24 hours. The quest for a newer adjuvant for nerve blocks continues [9].

Dexmedetomidine is a highly selective alpha-2 agonist, acting through a centrally mediated mechanism, having analgesic, anxiolytic, hemodynamic, sedative, and anesthetic sparing effects [10]. Thapa et al. [11] have demonstrated the effects of dexmedetomidine as an adjuvant to local anesthetic for prolonging the duration of postoperative analgesia in ACB in patients following anterior cruciate ligament (ACL) surgery. The authors conducted the study in ACL surgery patients which have difference in dermatome, myotome, osteotome, and duration of pain as compared to acute trauma patients undergoing below knee surgery. The authors did not administer the sciatic popliteal block (SPB), used a different dose of dexmedetomidine and did not perform any postoperative follow-up [11]. The published literature describes use of ACB and SPB for postoperative analgesia in lower limb surgery patients [6-8].

According to published literature, use of dexmedetomidine as an adjuvant in ACB and SPB for postoperative analgesia following spinal anesthesia in lower limb trauma patients is limited. The rationale for use of an adjuvant in nerve blocks is that it can lower the dosage of local anesthetic, reduce hemodynamic instability, allows the surgeon to evaluate the patient's movements of the lower limb, and also to perform active physiotherapy in the postoperative period [9]. Use of ropivacaine in ACB and SPB is a standard technique. We hypothesized that dexmedetomidine either as an adjuvant to postoperative nerve blocks or systemic dexmedetomidine with postoperative nerve blocks would reduce 48 hours postoperative cumulative tramadol consumption versus a control group in below knee trauma surgery patients.

\section{MATERIALS AND METHODS}

\section{Study design}

This randomized, placebo-controlled study was con- ducted at the Government Medical College and Hospital between April 7, 2017 and May 9, 2018. Follow-up was done in all patients after three months of surgery, from July 11, 2017 to August 12, 2018. The study adhered to the Good Clinical Practice quality standards and the ethical guidelines defined by the Declaration of Helsinki. The study was approved from the Ethics Committee of the Government Medical College and Hospital (EC/2016/0035), and registered with Clinical Trial Registry India (CTRI/2017/ 02/007955).

\section{Subjects}

Patients of American Society of Anesthesiologists (ASA) physical status I and II of both sexes, 18 to 65 years old, with a body mass index of $20-35 \mathrm{~kg} / \mathrm{m}^{2}$ and scheduled for below knee trauma surgery were screened for inclusion in the study. Exclusion criteria were as follows: a history of head injury and/or polytrauma, coagulopathy and bleeding disorders, peripheral neuropathy, local infection at the site of block, pregnant and lactating women, an inability to understand the functioning of the patient-controlled analgesia (PCA) pump and visual analogue scale (VAS), contraindication or allergy to study drugs, inability to perform dorsi- and plantar-flexion, hemodynamic instability, use of regular chronic pain management drugs for the last three months, and substance abuse. In the VAS for pain assessment, 0 stands for no pain and 10 stands for the worst imaginable pain [12]. Patients were enrolled by an anesthesia junior resident (AC). Concealment was done by putting group details in an opaque, sealed envelope. The envelope was opened, and allocated drug was prepared by an anesthesia resident not involved in the postoperative assessment of the patients. Blinding was ensured by the anesthesia resident by preparing syringes with a similar volume containing the drugs according to the allocated group. The SPB and ACB was performed by an anesthesiologist (VA, DT, AC). Patients were assessed in the postoperative period by a junior anesthesia resident (AC). The patient, the anesthesiologist performing the block, and the postoperative anesthesia assessor were blinded to group allocation.

\section{Anesthesia technique}

All patients were screened for inclusion and exclusion criteria for the study, and after fulfilling the criteria, patients were enrolled. Written informed consent was obtained from all patients who participated in this study. Patients consumed no solids for 8 hours and no water for 2 hours. Patient received tablet alprazolam $0.25 \mathrm{mg}$ and tablet pantoprazole $40 \mathrm{mg}$ orally the night before surgery and 2 hours 
prior to surgery.

All patients received mandatory anesthesia monitoring (AS5; Datex Ohmeda, Helsinki, Finland) and IV $500 \mathrm{~mL}$ of $0.9 \%$ normal saline (NS). A standard technique of subarachnoid block (SAB), with $3.2 \mathrm{~mL}$ of $0.5 \%$ bupivacaine heavy and $15 \mu$ g fentanyl $(0.3 \mathrm{~mL})$, to make a total of 3.5 $\mathrm{mL}$, was injected into the subarachnoid space in the $\mathrm{L}_{2}$ $\mathrm{L}_{3}$ or $\mathrm{L}_{3}-\mathrm{L}_{4}$ interspace. After completion of the surgery, IV paracetamol $1 \mathrm{~g}$ and IV tramadol $50 \mathrm{mg}$ were administered.

In the post anesthesia care unit 90 patients were randomized to one of the three groups $(n=30)$ using a computer-generated random number table.

\section{1) Group I (control group)}

Patients received perineural ACB with $16 \mathrm{~mL}$ of a solution ( $15 \mathrm{~mL}$ of $0.5 \%$ ropivacaine plus $1 \mathrm{~mL}$ of sterile $\mathrm{NS}=16 \mathrm{~mL}$ ) and perineural SPB with $21 \mathrm{~mL}$ of a solution $(20 \mathrm{~mL}$ of $0.15 \%$ ropivacaine plus $1 \mathrm{~mL}$ of sterile $\mathrm{NS}=21 \mathrm{~mL}$ ). In addition, patients received $10 \mathrm{~mL}$ of NS by IV administration.

\section{2) Group II (block Dex group)}

Patients received perineural ACB with $16 \mathrm{~mL}$ of a solution ( $15 \mathrm{~mL}$ of $0.5 \%$ ropivacaine $+0.5 \mu \mathrm{g} / \mathrm{kg}$ of dexmedetomidine in $1 \mathrm{~mL}$ of sterile $\mathrm{NS}=16 \mathrm{~mL}$ ) and perineural SPB in $21 \mathrm{~mL}$ of a solution $(20 \mathrm{~mL}$ of $0.15 \%$ ropivacaine $+0.5 \mu \mathrm{g} / \mathrm{kg}$ of dexmedetomidine in $1 \mathrm{~mL}$ of sterile $\mathrm{NS}=21 \mathrm{~mL}$ ). In addition, patients received $10 \mathrm{~mL}$ of NS by IV administration.

\section{3) Group III (systemic Dex group)}

Patients received perineural ACB with $16 \mathrm{~mL}$ of a solution ( $15 \mathrm{~mL}$ of $0.5 \%$ ropivacaine plus $1 \mathrm{~mL}$ of sterile $\mathrm{NS}=16 \mathrm{~mL}$ ) and perineural SPB with $21 \mathrm{~mL}$ of a solution $(20 \mathrm{~mL}$ of $0.15 \%$ ropivacaine plus $1 \mathrm{~mL}$ of sterile $\mathrm{NS}=21 \mathrm{~mL}$ ). In addition, patients received $1.0 \mu \mathrm{g} / \mathrm{kg}$ of dexmedetomidine in $10 \mathrm{~mL}$ of NS by IV administration.

\section{4) PNB}

Under strict asepsis, ACB was performed using a high frequency (5-10 MHz) ultrasound probe (Sonosite Inc., Bothell, WA). For ACB, the patient was in supine position with the operated leg positioned in abduction and external rotation. The ultrasound probe was placed in a transverse cross-sectional position on the mid-thigh. A 10 cm, 18-gauge Tuohy needle (Braun Medical, Melsungen, Germany) was inserted in-plane till the tip of the needle was placed lateral to the femoral artery and the saphenous nerve. Hydro-dissection was done with NS and a 20-gauge catheter was inserted $5 \mathrm{~cm}$ beyond the tip of the epidural needle. For the SPB, the patient was placed in a lateral position with the operated extremity kept non-dependent and straight. An ultrasound probe was placed at the popliteal crease and then traced upward $8-10 \mathrm{~cm}$ above, till the sciatic popliteal nerve was visualized superior to the popliteal artery. An 18-gauge Tuohy needle was introduced, in-plane from the lateral side, to pierce the fascia surrounding the sciatic popliteal nerve, and $5 \mathrm{~mL}$ of sterile NS was injected after careful aspiration. Following correct placement of the needle, a 20-gauge catheter was inserted and $5-8 \mathrm{~cm}$ of the catheter was kept inside the SPB nerve sheath and aseptic dressing was performed. The study drugs were administered to the patient according to group allocation only after the motor effect of the spinal anesthesia had worn off, and patients were able to perform dorsiand plantar-flexion of the operated limb. In the postoperative period, for patients with ankle splints or those who experienced difficulty in dorsi- and plantar-flexion, we used great toe flexion and extension as an alternative to removing the cast every time we assessed dorsi- and plantar-flexion.

Following this, all patients received perineural ACB $0.5 \%$ ropivacaine $15 \mathrm{~mL}$ every 6 hours, perineural SPB $0.15 \%$ ropivacaine $20 \mathrm{~mL}$ every 12 hours for 48 hours. Also, the IV PCA tramadol, paracetamol 1 g every 6 hours and ondansetron $8 \mathrm{mg}$ every 12 hours were given to the patients for 48 hours. The tramadol PCA pump had the following settings: a tramadol concentration of $10 \mathrm{mg} / \mathrm{mL}$, bolus dose of $2.0 \mathrm{~mL}$, lock-out interval of 20 minutes, and a dose limit of $350 \mathrm{mg}$ over 24 hours. Rescue analgesia was provided with IV diclofenac $75 \mathrm{mg}$ in $100 \mathrm{~mL}$ NS over 10 minutes if the patient had experienced a VAS score greater than 4 , in spite of the above multimodal analgesic regime.

\section{Assessment}

The primary outcome of the study was the postoperative cumulative tramadol consumption at 48 hours in patients following knee trauma surgery under spinal anesthesia. Cumulative tramadol consumption at other time points before 48 hours was observed as a secondary outcome. Other secondary outcomes were the time to the first tramadol PCA, the hemodynamic parameters, the VAS scores at rest [12], VAS scores on movement [12], Ramsay sedation score (RSS) [13], nausea or vomiting [14], patient satisfaction score (PSS) [15], quadriceps strength test [16], dorsiand plantar-flexion, sensory analgesia, rescue analgesic requirement, and any other complaints were recorded immediately after the block at $0,5,10,15,60$ minutes and at $4,6,12,18,24,30,36,42$, and 48 hours. At 24 hours and 48 hours post-operatively, the patients were asked to rate 
their satisfaction. An anesthesia resident, blinded to group allocation, took all the outcome measures. The PSS [15] was assessed using a five point scale, where 5 stands for very satisfied, 4 stands for satisfied, 3 stands for undecided, 2 stands for dissatisfied, and 1 stands for very dissatisfied. At discharge, the length of hospital stay (in days) was noted. After three months, patients were contacted by telephone and asked to rate their PSS, and pain assessment on the verbal numeric rating scale (VNRS) [17], both at rest and on movement. Decoding was done at the end of the study and data was analyzed using appropriate statistical tests.

\section{Statistical analysis}

To calculate the sample size for the present study, a few pilot cases were conducted in our hospital. The calculated effect size from the data was 0.35 using the formula $(\mathrm{f})=\mathrm{d} \times$ $1 / 2 \sqrt{(\mathrm{n}+1) / 3(\mathrm{n}-1)}$ where $\mathrm{d}=31 / 37.4=0.83, \mathrm{n}=$ the number of groups, and $d$ is the difference between the highest (106.6 mg) and lowest mean (74.62 mg) tramadol consumption of the control group with a standard deviation (SD) of $37.4 \mathrm{mg}$. To obtain a $30 \%$ decrease in mean tramadol consumption at 48 hours in the block Dex group or sys- temic Dex group as compared to the control group, with a power of 0.8 and a $95 \%$ confidence interval, 27 patients were required in each group. To compensate for dropouts, we decided to include 3 more patients per group. So, the total sample size of our study was 90 patients.

The normality of data was checked using KolmogorovSmirnov tests. For comparisons, one-way analysis of variance (ANOVA) with the least significant difference, as a post hoc test was used. The Kruskal-Wallis test or MannWhitney $U$-test was used for skewed continuous variables. For time related skews or ordinal data the Wilcoxon signed-rank test was applied. Proportions were compared using the chi-square or Fisher's exact test, depending on their applicability. The Kaplan-Meier curve was used to demonstrate the time to the first tramadol PCA analgesia. All the statistical tests were two-sided and were performed at a significance level of $\alpha=0.05$. Analysis was conducted using IBM SPSS Statistics ver. 22.0 (IBM Corp., Armonk, NY).

\section{RESULTS}

We assessed 105 patients for eligibility, and out of these, 15

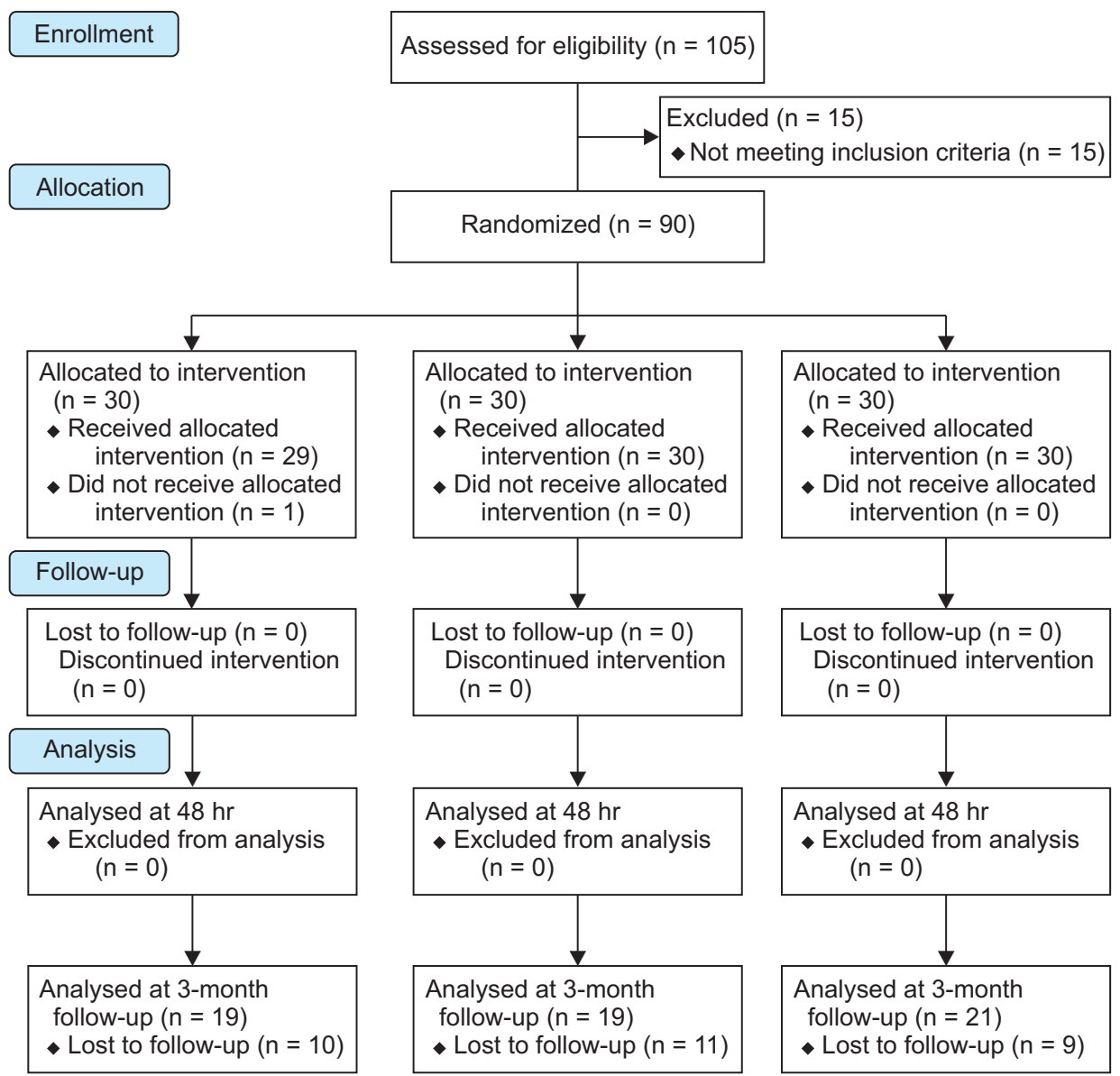

www.epain.org
Fig. 1. CONSORT flow diagram of patient enrollment. 
patients were excluded. Hence, a total of 90 patients were randomized (Fig. 1). One patient was randomized but not analyzed due to surgical reasons. The patient was from the control group and was managed as per intension to treat. The baseline demographics failed to show statistical differences in the study groups (Table 1). The enrolled patients in both the groups were young in age and were scheduled to undergo acute orthopedic bone trauma surgery, with 68 patients having fractured both bone legs and 22 patients with a fractured tibia only. The type of surgery failed to show any statistical difference between the groups $(P=0.69)$.

The normality of the quantitative data for tramadol consumption was checked by means of the KolmogorovSmirnov tests for normality. The data of tramadol consumption was found to be skewed and two groups were compared using the Mann-Whitney $U$-test. The cumulative mean \pm SD (interquartile range [IQR]) tramadol consumption at 48 hours was $64.83 \pm 51.17 \mathrm{mg}(40-80 \mathrm{mg})$ in the control group versus $41.33 \pm 38.57 \mathrm{mg}(20-60 \mathrm{mg})$ in the block Dex group $(P=0.008)$, using the Mann-Whitney $U$-test. The mean \pm SD (IQR) of cumulative tramadol consumption at 48 hours of the systemic Dex group was $43.33 \pm$ $19.00 \mathrm{mg}(20-60 \mathrm{mg})$ versus $64.83 \pm 51.17 \mathrm{mg}(40-80 \mathrm{mg})$ in the control group $(P=0.03)$. The cumulative postoperative tramadol consumption at $4,6,12,18,24,30,36$, and 42 hours following surgery was statistically reduced in patients receiving block Dex vs. the control group (Table 2, Fig. 2). The study was not powered to detect the difference in block Dex versus systemic Dex for cumulative postoperative tramadol consumption. The time to the first bolus mean \pm SD (range) of PCA tramadol was earlier in the control group as compared to the block Dex group $5.17 \pm 2.65$ hours (0-12 hr) vs. $6.47 \pm 3.35$ hours $(0-12 \mathrm{hr})(P=0.04)$. The Kaplan-Meier curve showed that the number of patients taking IV PCA tramadol at 4-12 hours was greater in the control group as compared to the systemic Dex group and block Dex group (Fig. 3).

The perioperative median VAS score at rest and on movement was comparable (Fig. 4). The hemodynamic parameters were analyzed using one-factor analysis ANOVA and a clinically significant difference was detected. The hemodynamic values were within the normal physiological range at all time intervals in the patients of all the three groups. The mean \pm SD (range) of RSS at 15 minutes was $2.07 \pm 0.59$ (1-5) in the control group, $1.93 \pm 0.37$ (1-3) in the block Dex group and $2.23 \pm 0.50$ (1-3) in the systemic Dex group $(P=0.01)$, but all patients were arousable on command and no patient was deeply sedated. During the rest of the time points RSS failed to show a statistical difference. The quadriceps strength test, sensory analgesia in the areas of both the SPB and ACB, as well as dorsi- and plantar-flexion failed to show any statistical difference in the patients from all three groups in follow-up to 48 hours postoperatively. There was no requirement for rescue analgesia in any patient during the period of study. The PSS failed to show any statistical difference between the groups at 24 hours and 48 hours postoperatively. There were no adverse effects during the study. The duration of hospital stay in all the three groups was comparable to that of the hospital protocol $(P=0.55)$.

At three months postoperatively $38 \%$ of patients had been loss to follow-up. The remaining $62 \%$ patients reported comparable results in VNRS scores at rest $(P=0.19)$, on movement $(P=0.23)$, and in their PSS $(P=0.13)$. No patient reported any block-related complications.

\section{DISCUSSION}

This study demonstrates a reduction in postoperative cumulative tramadol consumption at 48 hours in patients receiving perineural or systemic dexmedetomidine with the ACB and SPB as compared to a control group in patients undergoing below knee trauma surgeries under spinal anesthesia.

The use of perineural dexmedetomidine blocks hyperpolarization activated cation current [18]. These currents

Table 1. Characteristics of 90 Patients Receiving Postoperative Analgesia with Adductor Canal Block and Sciatic Popliteal Block

\begin{tabular}{|c|c|c|c|c|}
\hline Characteristic & Control group $(n=30)$ & Block Dex group $(n=30)$ & Systemic Dex group $(n=30)$ & $P$ value \\
\hline Age (yr) & $38.4 \pm 13.4$ & $33.6 \pm 11.4$ & $36.8 \pm 12.8$ & 0.33 \\
\hline $\mathrm{M} / \mathrm{F}$ & $26(86.7) / 4(13.3)$ & $28(93.3) / 2(6.7)$ & $27(90.0) / 3(10.0)$ & 0.69 \\
\hline Height (cm) & $170.0 \pm 8.1$ & $169.1 \pm 6.8$ & $169.4 \pm 7.4$ & 0.89 \\
\hline Weight (kg) & $66.2 \pm 12.8$ & $63.3 \pm 9.9$ & $67.4 \pm 13.2$ & 0.40 \\
\hline $\mathrm{BMI}\left(\mathrm{kg} / \mathrm{m}^{2}\right)$ & $22.8 \pm 3.6$ & $22.1 \pm 3.3$ & $23.3 \pm 3.2$ & 0.39 \\
\hline ASA I & $25(83.3)$ & $29(96.7)$ & $28(93.3)$ & 0.17 \\
\hline ASA II & $5(16.7)$ & $1(3.3)$ & $2(6.7)$ & \\
\hline
\end{tabular}

Values are presented as mean \pm standard deviation or number (\%).

Dex: dexmedetomidine, BMI: body mass index, ASA: American Society of Anesthesiologists. 
Table 2. Postoperative Comparison of Cumulative Tramadol Consumption (from 0 min in PACU to $48 \mathrm{hr}$ ) in Patients Who Received Post-operative ACB and SPB

\begin{tabular}{|c|c|c|c|c|c|}
\hline \multirow[b]{2}{*}{ Time interval } & \multirow[b]{2}{*}{$\begin{array}{l}\text { Control group } \\
\qquad(\mathrm{n}=29)^{\mathrm{a}}\end{array}$} & \multirow[b]{2}{*}{$\begin{array}{l}\text { Block Dex group } \\
\qquad(n=30)\end{array}$} & \multirow{2}{*}{$\begin{array}{l}\text { Systemic Dex group } \\
\qquad(\mathrm{n}=30)\end{array}$} & \multicolumn{2}{|c|}{$P$ value } \\
\hline & & & & $\begin{array}{l}\text { Control vs. block } \\
\text { Dex group }\end{array}$ & $\begin{array}{c}\text { Control vs. systemic } \\
\text { Dex group }\end{array}$ \\
\hline $0 \mathrm{~min}$ & $\begin{array}{c}0.00 \pm 0.00 \\
(0.00-0.00[0-0])\end{array}$ & $\begin{array}{c}0.00 \pm 0.00 \\
(0.00-0.00[0-0])\end{array}$ & $\begin{array}{c}0.00 \pm 0.00 \\
(0.00-0.00[0-0])\end{array}$ & - & - \\
\hline $5 \mathrm{~min}$ & $\begin{array}{c}0.00 \pm 0.00 \\
(0.00-0.00[0-0])\end{array}$ & $\begin{array}{c}0.00 \pm 0.00 \\
(0.00-0.00[0-0])\end{array}$ & $\begin{array}{c}0.00 \pm 0.00 \\
(0.00-0.00[0-0])\end{array}$ & - & - \\
\hline $10 \mathrm{~min}$ & $\begin{array}{c}0.00 \pm 0.00 \\
(0.00-0.00[0-0])\end{array}$ & $\begin{array}{c}0.00 \pm 0.00 \\
(0.00-0.00[0-0])\end{array}$ & $\begin{array}{c}0.00 \pm 0.00 \\
(0.00-0.00[0-0])\end{array}$ & - & - \\
\hline $15 \mathrm{~min}$ & $\begin{array}{c}0.00 \pm 0.00 \\
(0.00-0.00[0-0])\end{array}$ & $\begin{array}{c}0.00 \pm 0.00 \\
(0.00-0.00[0-0])\end{array}$ & $\begin{array}{c}0.00 \pm 0.00 \\
(0.00-0.00[0-0])\end{array}$ & - & - \\
\hline $1 \mathrm{hr}$ & $\begin{array}{c}0.00 \pm 0.00 \\
(0.00-0.00[0-0])\end{array}$ & $\begin{array}{c}0.00 \pm 0.00 \\
(0.00-0.00[0-0])\end{array}$ & $\begin{array}{c}0.00 \pm 0.00 \\
(0.00-0.00[0-0])\end{array}$ & - & - \\
\hline $4 \mathrm{hr}$ & $\begin{array}{c}7.59 \pm 13.54 \\
(0-20[0-60])\end{array}$ & $\begin{array}{l}2.67 \pm 11.43 \\
(0-0[0-60])\end{array}$ & $\begin{array}{l}5.33 \pm 10.42 \\
(0-5[0-40])\end{array}$ & $0.02 *$ & 0.52 \\
\hline $6 \mathrm{hr}$ & $\begin{array}{c}28.28 \pm 24.22 \\
(20-40[0-120])\end{array}$ & $\begin{array}{r}18.67 \pm 19.61 \\
(0-20[0-100])\end{array}$ & $\begin{array}{r}22.00 \pm 15.18 \\
(20-40[0-60])\end{array}$ & $0.04 *$ & 0.30 \\
\hline $12 \mathrm{hr}$ & $\begin{array}{c}49.66 \pm 35.71 \\
(20-60[0-180])\end{array}$ & $\begin{array}{c}33.33 \pm 23.68 \\
(20-40[0-120])\end{array}$ & $\begin{array}{l}38.00 \pm 27.05 \\
(20-45[20-80])\end{array}$ & $0.03 *$ & 0.14 \\
\hline $18 \mathrm{hr}$ & $\begin{array}{c}60.69 \pm 41.57 \\
(40-80[0-200])\end{array}$ & $\begin{array}{c}38.00 \pm 31.67 \\
(20-45[0-140])\end{array}$ & $\begin{array}{l}40.67 \pm 17.80 \\
(20-60[20-80])\end{array}$ & $0.005 *$ & $0.01 *$ \\
\hline $24 \mathrm{hr}$ & $\begin{array}{c}62.76 \pm 44.63 \\
(40-80[0-200])\end{array}$ & $\begin{array}{c}40.67 \pm 36.19 \\
(20-60[0-160])\end{array}$ & $\begin{array}{l}43.33 \pm 19.00 \\
(20-60[20-80])\end{array}$ & $0.008 *$ & $0.03 *$ \\
\hline $30 \mathrm{hr}$ & $\begin{array}{c}64.14 \pm 48.81 \\
(40-80[0-220])\end{array}$ & $\begin{array}{c}41.33 \pm 38.57 \\
(20-60[0-180])\end{array}$ & $\begin{array}{l}43.33 \pm 19.00 \\
(20-60[20-80])\end{array}$ & $0.008^{*}$ & $0.03 *$ \\
\hline $36 \mathrm{hr}$ & $\begin{array}{c}64.83 \pm 51.17 \\
(40-80[0-240])\end{array}$ & $\begin{array}{c}41.33 \pm 38.57 \\
(20-60[0-180])\end{array}$ & $\begin{array}{l}43.33 \pm 19.00 \\
(20-60[20-80])\end{array}$ & $0.008^{*}$ & $0.03 *$ \\
\hline $42 \mathrm{hr}$ & $\begin{array}{c}64.83 \pm 51.17 \\
(40-80[0-240])\end{array}$ & $\begin{array}{c}41.33 \pm 38.57 \\
(20-60[0-180])\end{array}$ & $\begin{array}{l}43.33 \pm 19.00 \\
(20-60[20-80])\end{array}$ & $0.008^{*}$ & $0.03 *$ \\
\hline $48 \mathrm{hr}$ & $\begin{array}{c}64.83 \pm 51.17 \\
(40-80[0-240])\end{array}$ & $\begin{array}{c}41.33 \pm 38.57 \\
(20-60[0-180])\end{array}$ & $\begin{array}{l}43.33 \pm 19.00 \\
(20-60[20-80])\end{array}$ & $0.008^{*}$ & $0.03 *$ \\
\hline
\end{tabular}

Values are presented as mean \pm standard deviation (interquartile range [range]).

PACU: post anesthesia care unit, ACB: adductor canal block, SPB: sciatic popliteal block, Dex: dexmedetomidine.

${ }^{a}$ One patient was randomized but not analyzed due to surgical reasons.

$\star P<0.05$ statistically significant.

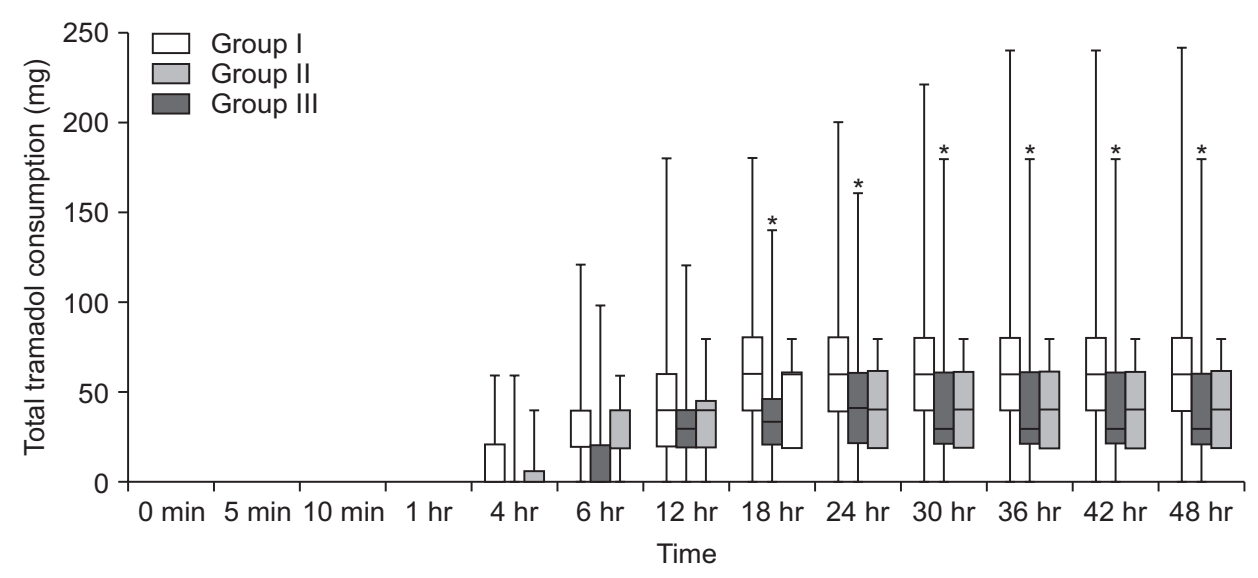

Fig. 2. Box-and-whisker plot showing postoperative total tramadol consumption (baseline to $48 \mathrm{hr}$ postoperatively) in patients receiving adductor canal block and sciatic popliteal block. Group I: control group, group II: block Dex group, group III: systemic Dex group, Dex: dexmedetomidine. Values are presented as median (interquartile range [range]). ${ }^{*} P<0.05$ compared with control group. are important for re-establishing the resting membrane potential of a nerve and, when blocked with perineural dexmedetomidine, lead to prolonged hyperpolarization, and potentiation of sensory analgesia $[18,19]$. The preclinical data suggests that clonidine selectively blocks sensory $\mathrm{C}$ fibers as compared to A $\alpha$ fibers. It is not yet proven in 
a clinical trial that this mechanism holds true for perineural dexmedetomidine as well. The other mechanism of perineural dexmedetomidine is an alpha-2 receptorindependent inhibitory mechanism which reduces release of norepinephrine and the action potentials of nerve fibers resulting in analgesia. Perineural dexmedetomidine (0.5$1 \mu \mathrm{g} / \mathrm{kg}$ ) with local anesthetic increases the duration of

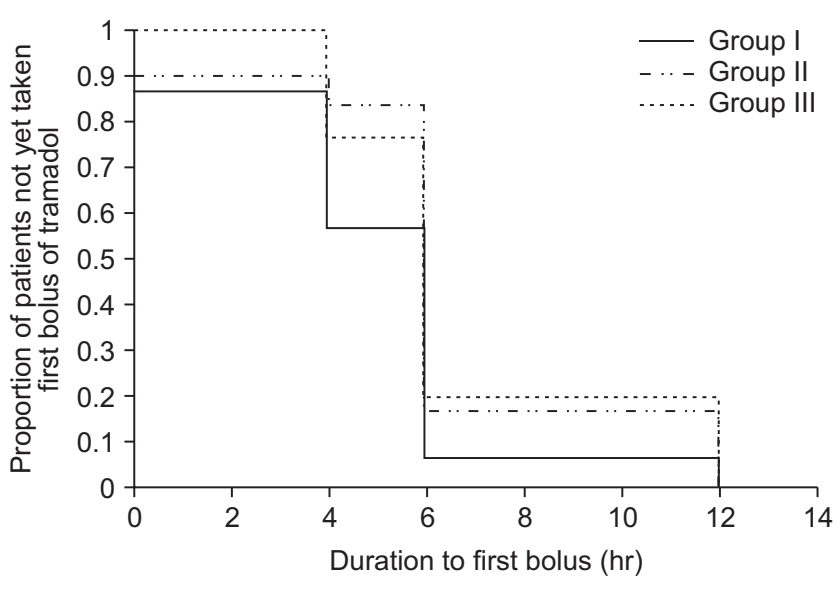

Fig. 3. The Kaplan-Meier curve demonstrates the time on $x$-axis and proportion of patients who did not take tramadol bolus on y-axis. Group I: control group, group II: block Dex group, group III: systemic Dex group, Dex: dexmedetomidine. analgesia up to $4-5$ hours [20,21]. However, a difference of $\cong 1.5$ hours was observed regarding the first rescue analgesic in patients receiving perineural dexmedetomidine versus the control group. In a recently conducted study, the authors demonstrated a prolongation by 2 hours in patients receiving the ACB with $1 \mu \mathrm{g} / \mathrm{kg}$ as compared to ropivacaine alone [22]. The peak systemic levels of perineural dexmedetomidine occurs at 30 minutes and has a halflife of 2 hours [23]. Fritsch et al. [23] used a single shot of perineural dexmedetomidine in the interscalene brachial plexus block (BPB) and reported analgesia up to 18 hours postoperatively. Perineural dexmedetomidine enhances the local anesthetic potency via the peripheral $\alpha-2$ adrenoreceptor subtype [24]. We observed a significant difference in PCA tramadol consumption after 4 hours (the effect of spinal anesthesia started to reduce and fade away) which continued up to 48 hours postoperatively in the block Dex group as compared to the control group.

In the present study patients in the systemic Dex group demonstrated a statistically significant postoperative tramadol sparing effect after 18 hours as compared to the control group. Systemic dexmedetomidine demonstrates analgesia due to its action on $\alpha-2$ agonists (central action) in the locus coeruleus and inhibition on the release of substance $P$ at the level of the dorsal root neuron [10]. The

A

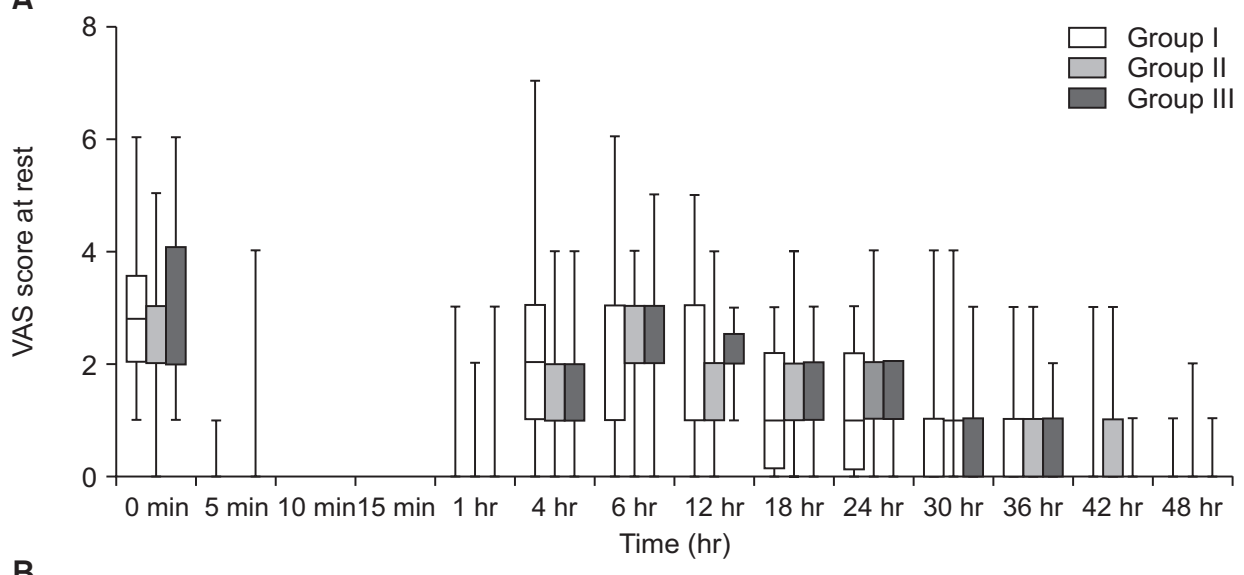

B

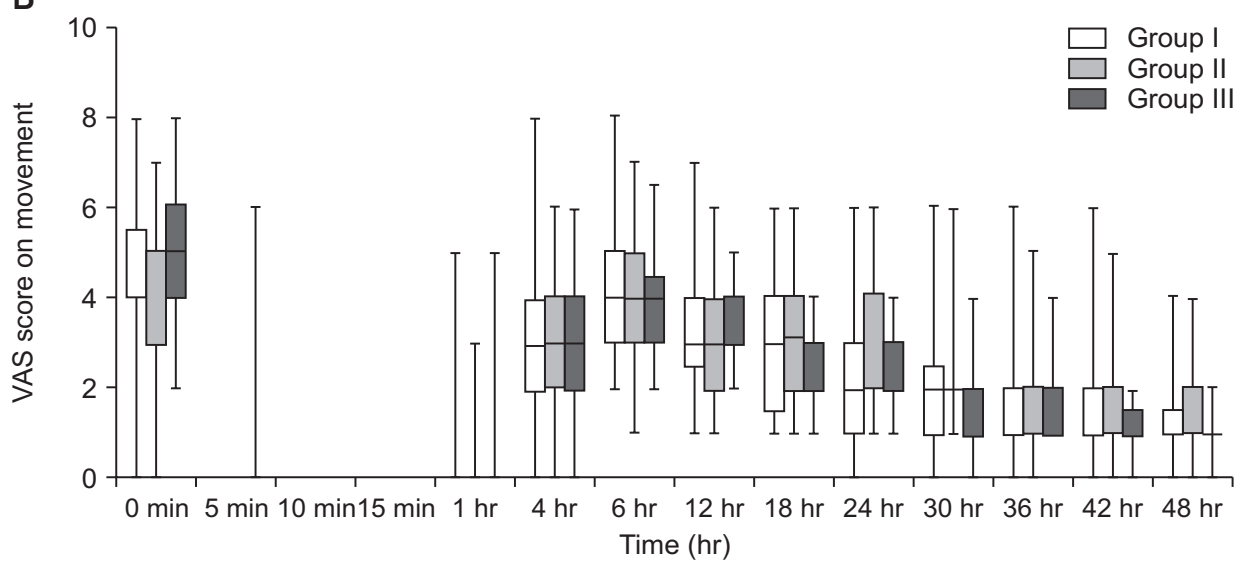

Fig. 4. Box-and-whisker plot showing (A) postoperative visual analogue scale (VAS) score at rest and (B) postoperative VAS on movement of patients receiving postoperative analgesia with adductor canal block and sciatic popliteal block. Group I: control group, group II: block Dex group, group III: systemic Dex group, Dex: dexmedetomidine. Values are presented as median (interquartile range [range]). 
published literature reports that when systemic dexmedetomidine is administered in patients receiving $\mathrm{SAB}$, the duration of the sensory block is prolonged by at least $34 \%$, the motor block by at least $17 \%$, and the time to the first analgesic requirement is also increased by at least $53 \%$ [21]. In a randomized controlled trial, a single dose of IV dexmedetomidine did not improve postoperative analgesia and opioid sparing at 4,8 , and 24 hours after cesarean section under regional anesthesia. The authors observed that the SAB possibly overlapped the postoperative analgesic effect of IV dexmedetomidine [25]. This observation is supported with the evidence that IV dexmedetomidine has an onset time of 15 minutes, a distribution half-life of 6 minutes, and an elimination half-life of 2.1-3.1 hours. The metabolites of dexmedetomidine are inactive at the $\alpha-2$ receptors [26-28]. Hence, any systemic effect of dexmedetomidine beyond this period would not be expected. In a metanalysis, postoperative IV dexmedetomidine with an opioid, administered by PCA, showed superior analgesia, an opioid sparing effect, as well as demonstrating reduced side effects and greater PSS. None of the studies included in the metanalysis had examined patients receiving a single dose perineural dexmedetomidine versus systemic dexmedetomidine for opioid sparing in trauma patients following lower limb surgeries [25,29].

In the present study, instead of a fixed dose of dexmedetomidine we chose $1 \mu \mathrm{g} / \mathrm{kg}$ based on the published literature on humans and animals $[18,19,30,31]$. Sinha et al. [30] conducted a randomized, double blind study on 90 patients undergoing upper limb surgeries under a BPB. The authors failed to show a statistical difference in the duration of analgesia as well as sensory and motor blockade comparing perineural $1 \mu \mathrm{g} / \mathrm{kg}$ and $2 \mu \mathrm{g} / \mathrm{kg}$ dexmedetomidine, but found a higher incidence of bradycardia and hypotension in the patients receiving $2 \mu \mathrm{g} / \mathrm{kg}$ perineural dexmedetomidine. The authors concluded that $1 \mu \mathrm{g} / \mathrm{kg}$ perineural dexmedetomidine is a good balance between safety and efficacy. The basis of the dose selection of perineural dexmedetomidine also draws its support from a few animal studies $[18,19]$. Brummett et al. [31] concluded that $100 \mu \mathrm{g}$ dexmedetomidine was the optimal dose for balancing the prolongation of the nerve block and sedation intensity. Hence, we chose $1 \mu \mathrm{g} / \mathrm{kg}$ dexmedetomidine as the optimal dose both for patients receiving either systemic or perineural dexmedetomidine.

The mechanism of sedation following systemic dexmedetomidine is inhibition of the locus coeruleus, which further stimulates ventrolateral preoptic nucleus firing and behaves like non-rapid eye movement sleep [13]. At 15 minutes, the patients receiving systemic dexmedetomidine showed a higher RSS than the control group, while those receiving perineural dexmedetomidine showed the lowest RSS. Intervenous dexmedetomidine, which produces a sedative effect, has its onset effect at 15 minutes [26,27]. However, the results of the RSS may be affected by ethnicity, age, body size, cardiac output, hypoproteinemia, and hepatic metabolism [32].

In the present study, none of the patients exhibited motor blockade. Lollo et al. [7] demonstrated a similar standard that all patients should be able to perform toe plantar flexion immediately and after 24 hours postoperatively. The importance of any clinical study is based on patient satisfaction, and in this study, there was showed no statistical difference in PSS in the three groups at 24 and 48 hours postoperatively. This was probably due to the fact that the VAS score was $<4$ at all time points in all the three groups. The VAS score $<4$ was ensured during the study with constant VAS monitoring, local anesthetic boluses in all groups and freedom to use PCA tramadol for all patients.

Only a few studies have mentioned PSS as a secondary outcome [33]. Fisker et al. [34], Joe et al. [35], and Hu et al. [36] reported similar observations to those in the present study. There are few studies with postoperative follow-up in trauma patients [37-39]. We had a follow-up of $62 \%$ of patients at the end of three months, and patients reported good pain relief and PSS.

There are a few limitations in the present study. Firstly, the time duration of the initiation of the SAB, and the administration of study drugs in the peripheral catheters was not recorded. However, we followed the standardization of the patient's ability to demonstrate ankle dorsi- and planter-flexion or great toe flexion and extension movements before administration of the allocated study drug in all patients. Secondly, only ASA grade I and II patients enrolled in the study. Higher ASA grades of patients need to be evaluated in the future. Thirdly, we used only a single dose of dexmedetomidine in the patients. Studies with repeated doses of dexmedetomidine may be conducted in the future. However, the risk versus benefit, in terms of safety in studies, may also be evaluated. Fourthly, the study was not powered to detect difference between the block Dex group and the systemic Dex group.

In conclusion, perineural or systemic dexmedetomidine in ACB and SPB reduced postoperative tramadol consumption as compared to a control group at 48 hours postoperatively in patients undergoing knee trauma surgery under spinal anesthesia.

\section{CONFLICT OF INTEREST}

No potential conflict of interest relevant to this article was reported. 


\section{FUNDING}

No funding to declare.

\section{ORCID}

Vanita Ahuja, https://orcid.org/0000-0001-5336-325X

Deepak Thapa, https://orcid.org/0000-0002-4383-8183

Anjuman Chander, https://orcid.org/0000-0003-1281-3909

Satinder Gombar, https://orcid.org/0000-0003-1065-4377

Ravi Gupta, https://orcid.org/0000-0002-9705-9863

Sandeep Gupta, https://orcid.org/0000-0003-4866-5303

\section{REFERENCES}

1. Jones J Jr, Southerland W, Catalani B. The importance of optimizing acute pain in the orthopedic trauma patient. Orthop Clin North Am 2017; 48: 445-65.

2. Wiznia DH, Zaki T, Leslie MP, Halaszynski TM. Complexities of perioperative pain management in orthopedic trauma. Curr Pain Headache Rep 2018; 22: 58.

3. Gadsden J, Warlick A. Regional anesthesia for the trauma patient: improving patient outcomes. Local Reg Anesth 2015; 8: 45-55.

4. Christie IW, McCabe S. Major complications of epidural analgesia after surgery: results of a six-year survey. Anaesthesia 2007; 62: 335-41.

5. Sites BD, Antonakakis JG. Ultrasound guidance in regional anesthesia: state of the art review through challenging clinical scenarios. Local Reg Anesth 2009; 2: 1-14.

6. Davies AF, Segar EP, Murdoch J, Wright DE, Wilson IH. Epidural infusion or combined femoral and sciatic nerve blocks as perioperative analgesia for knee arthroplasty. $\mathrm{Br} \mathrm{J}$ Anaesth 2004; 93: 368-74.

7. Lollo L, Bhananker S, Stogicza A. Postoperative sciatic and femoral or saphenous nerve blockade for lower extremity surgery in anesthetized adults. Int J Crit Illn Inj Sci 2015; 5: 232-6.

8. YaDeau JT, Paroli L, Fields KG, Kahn RL, LaSala VR, JulesElysee KM, et al. Addition of dexamethasone and buprenorphine to bupivacaine sciatic nerve block: a randomized controlled trial. Reg Anesth Pain Med 2015; 40: 321-9.

9. Jeon YH. The use of adjuvants to local anesthetics: benefit and risk. Korean J Pain 2018; 31: 233-34.

10. Kauppila T, Kemppainen P, Tanila H, Pertovaara A. Effect of systemic medetomidine, an alpha 2 adrenoceptor agonist, on experimental pain in humans. Anesthesiology 1991; 74: 3-8.

11. Thapa D, Ahuja V, Pandey K, Gombar S, Gupta R. Evaluation of analgesic efficacy of dexmedetomidine as adjuvant with ropivacaine in ultrasound-guided adductor canal block in patients following anterior cruciate ligament reconstruction surgeries. Br J Pain 2019; 13: 91-8.

12. Gaumann D, Forster A, Griessen M, Habre W, Poinsot O, Della Santa D. Comparison between clonidine and epinephrine admixture to lidocaine in brachial plexus block. Anesth Analg 1992; 75: 69-74.

13. Miaskowski C, Crews J, Ready LB, Paul SM, Ginsberg B. Anesthesia-based pain services improve the quality of postoperative pain management. Pain 1999; 80: 23-9.

14. Carney J, McDonnell JG, Ochana A, Bhinder R, Laffey JG. The transversus abdominis plane block provides effective postoperative analgesia in patients undergoing total abdominal hysterectomy. Anesth Analg 2008; 107: 2056-60.

15. Sim JH, Yu HJ, Kim ST. The effects of different loading doses of dexmedetomidine on sedation. Korean J Anesthesiol 2014; 67: 8-12.

16. Fukuda TY, Fingerhut D, Moreira VC, Camarini PM, Scodeller NF, Duarte A Jr, et al. Open kinetic chain exercises in a restricted range of motion after anterior cruciate ligament reconstruction: a randomized controlled clinical trial. Am J Sports Med 2013; 41: 788-94.

17. Holdgate A, Asha S, Craig J, Thompson J. Comparison of a verbal numeric rating scale with the visual analogue scale for the measurement of acute pain. Emerg Med (Fremantle) 2003; 15: 441-6.

18. Trein TA, Floriano BP, Wagatsuma JT, Ferreira JZ, da Silva GL, Dos Santos PS, et al. Effects of dexmedetomidine combined with ropivacaine on sciatic and femoral nerve blockade in dogs. Vet Anaesth Analg 2017; 44: 144-53.

19. Brummett CM, Hong EK, Janda AM, Amodeo FS, Lydic R. Perineural dexmedetomidine added to ropivacaine for sciatic nerve block in rats prolongs the duration of analgesia by blocking the hyperpolarization-activated cation current. Anesthesiology 2011; 115: 836-43.

20. Lin YN, Li Q, Yang RM, Mao ZX, Liu JC. Addition of dexmedetomidine to ropivacaine improves cervical plexus block. Acta Anaesthesiol Taiwan 2013; 51: 63-6.

21. Abdallah FW, Abrishami A, Brull R. The facilitatory effects of intravenous dexmedetomidine on the duration of spinal anesthesia: a systematic review and meta-analysis. Anesth Analg 2013; 117: 271-8.

22. Andersen JH, Grevstad U, Siegel H, Dahl JB, Mathiesen O, Jæger P. Does dexmedetomidine have a perineural mechanism of action when used as an adjuvant to ropivacaine?: a paired, blinded, randomized trial in healthy volunteers. Anesthesiology 2017; 126: 66-73.

23. Fritsch G, Danninger T, Allerberger K, Tsodikov A, Felder TK, Kapeller M, et al. Dexmedetomidine added to ropivacaine extends the duration of interscalene brachial plexus blocks for elective shoulder surgery when compared with ropivacaine alone: a single-center, prospective, triple-blind, ran- 
domized controlled trial. Reg Anesth Pain Med 2014; 39: $37-$ 47.

24. Yoshitomi T, Kohjitani A, Maeda S, Higuchi H, Shimada M, Miyawaki T. Dexmedetomidine enhances the local anesthetic action of lidocaine via an alpha-2A adrenoceptor. Anesth Analg 2008; 107: 96-101.

25. Nie Y, Liu Y, Luo Q, Huang S. Effect of dexmedetomidine combined with sufentanil for post-caesarean section intravenous analgesia: a randomised, placebo-controlled study. Eur J Anaesthesiol 2014; 31: 197-203.

26. Bhana N, Goa KL, McClellan KJ. Dexmedetomidine. Drugs 2000; 59: 263-8.

27. Karol MD, Maze M. Pharmacokinetics and interaction pharmacodynamics of dexmedetomidine in humans. Best Pract Res Clin Anaesthesiol 2000; 14: 261-9.

28. Lee S, Kim BH, Lim K, Stalker D, Wisemandle W, Shin SG, et al. Pharmacokinetics and pharmacodynamics of intravenous dexmedetomidine in healthy Korean subjects. J Clin Pharm Ther 2012; 37: 698-703.

29. Peng K, Liu HY, Wu SR, Cheng H, Ji FH. Effects of combining dexmedetomidine and opioids for postoperative intravenous patient-controlled analgesia: a systematic review and metaanalysis. Clin J Pain 2015; 31: 1097-104.

30. Sinha C, Kumar A, Kumari P, Singh AK, Sharma S, Kumar A, et al. Comparison of two doses of dexmedetomidine for supraclavicular brachial plexus block: a randomized controlled trial. Anesth Essays Res 2018; 12: 470-4.

31. Brummett CM, Padda AK, Amodeo FS, Welch KB, Lydic R. Perineural dexmedetomidine added to ropivacaine causes a dose-dependent increase in the duration of thermal antinociception in sciatic nerve block in rat. Anesthesiology 2009; 111: 1111-9.
32. Weerink MAS, Struys MMRF, Hannivoort LN, Barends CRM, Absalom AR, Colin P. Clinical pharmacokinetics and pharmacodynamics of dexmedetomidine. Clin Pharmacokinet 2017; 56: 893-913.

33. Vorobeichik L, Brull R, Abdallah FW. Evidence basis for using perineural dexmedetomidine to enhance the quality of brachial plexus nerve blocks: a systematic review and metaanalysis of randomized controlled trials. Br J Anaesth 2017; 118: 167-81.

34. Fisker AK, Iversen BN, Christensen S, Linde F, Nielsen KK, Børglum J, et al. Combined saphenous and sciatic catheters for analgesia after major ankle surgery: a double-blinded randomized controlled trial. Can J Anaesth 2015; 62: 875-82.

35. Joe HB, Choo HS, Yoon JS, Oh SE, Cho JH, Park YU. Adductor canal block versus femoral nerve block combined with sciatic nerve block as an anesthetic technique for hindfoot and ankle surgery: a prospective, randomized noninferiority trial. Medicine (Baltimore) 2016; 95: e5758.

36. Hu X, Li J, Zhou R, Wang Q, Xia F, Halaszynski T, et al. Dexmedetomidine added to local anesthetic mixture of lidocaine and ropivacaine enhances onset and prolongs duration of a popliteal approach to sciatic nerve blockade. Clin Ther 2017; 39: 89-97.el.

37. Rivara FP, Mackenzie EJ, Jurkovich GJ, Nathens AB, Wang J, Scharfstein DO. Prevalence of pain in patients 1 year after major trauma. Arch Surg 2008; 143: 282-7.

38. Aaland MO, Marose K, Zhu TH. The lost to trauma patient follow-up: a system or patient problem. J Trauma Acute Care Surg 2012; 73: 1507-11.

39. Goldsmith H, Curtis K, McCloughen A. Incidence, intensity, and impact of pain in recently discharged adult trauma patients: an exploratory study. J Trauma Nurs 2017; 24: 102-9. 